\title{
Methodological considerations of digital video observation: Beyond conversation analysis
}

\section{Christopher Pearce}

Clinical Advisor (Research), Melbourne East General Practice Network, Melbourne, VIC, Australia; Honorary Senior Lecturer, University of Melbourne, Melbourne, VIC, Australia; Visiting Fellow, Australian National University, Canberra, ACT, Australia

\section{Michael ARnold}

Department of History and Philosophy of Science, University of Melbourne, Melbourne, VIC, Australia

\section{Christine Phillips}

Academic Unit of General Practice and Community Health, Australian National University,

Canberra, ACT, Australia

\section{KATHRYN DWAN}

Academic Unit of General Practice and Community Health, Australian National University, Canberra, ACT, Australia

\section{ABSTRACT}

This paper discusses some of the methodological issues of using digital video data in observational studies. It is based on the authors' experiences in research involving medical consultations. Previous observational studies in this field have used either direct observation or analogue videotapes. Traditionally, analysis is then done on transcriptions of the tapes, using conversation analysis or other techniques. These techniques were formed and created using largely analogue audiotapes. We will demonstrate how digital video increases the richness of data, such that conversation analysis becomes interaction analysis. Additionally, we argue that digital video changes the relationship between reader, researcher and data. A consideration of these changes is important to framing a comprehensive methodological approach to using digital video observation. Digital video needs to be considered in terms of what it offers in and of itself, rather than relating it to other techniques.

Keywords: qualitative research, observational techniques, methodology, physician-patient relationship, video observation, hermeneutics

\section{NOW AVAILABLE}

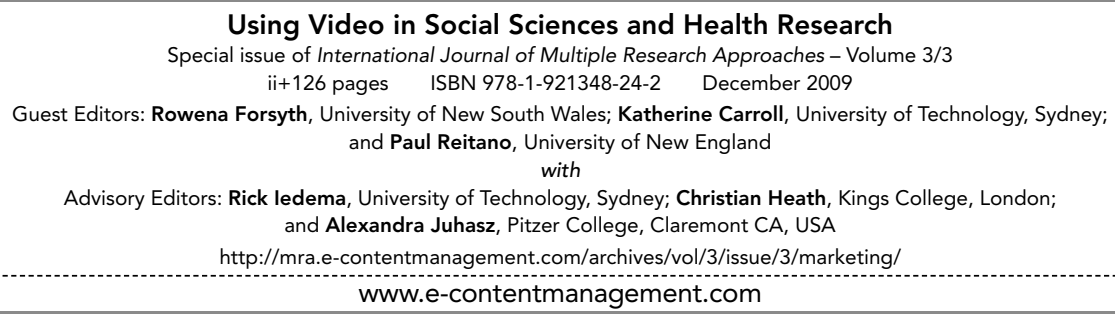




\section{Observational data}

Not wrung from speculations and subtleties, but from common sense and observation; not picked from the leaves of any author, but bred amongst the weeds and tares of mine own brain.

Sir Thomas Browne, Religio Medicii (1643)

П he use of observational techniques in scientific inquiry is as old as those inquiries themselves. Enlightenment scientists such as Jenner, Morgagni and Harvey changed how we think about disease by observing the world around them. Yet in contemporary fields of inquiry, observational techniques tend to be corralled within the social sciences, especially anthropology (with its foundational method ethnography) and sociology. For health researchers the rigour of the randomised controlled trial is seen to be superior to the softer, less valid techniques within the realm of qualitative enquiry. However not all questions can be answered by the Popperian scientific method with its focus on rigorous testing of a defined, falsifiable hypothesis (Popper, 1980), leading to randomised trials, pre and post test experimental interventions and other methods predominantly associated with the natural and physical sciences. Qualitative techniques are well positioned for the 'systematic collection, organisation and interpretation of textual material obtained from talk or observation, which allow the exploration of social events as experienced by individuals in their natural context' (Malterud, 2001b).

Observational techniques have traditionally used a human observer, one clearly identifiable or alternatively concealed by anonymity or devices such as one-way mirrors (Mason, 2002). Audiotapes are also used as data collection devices and newer technologies such as analogue and now digital video have created other possibilities for the observation of social interactions. These newer technologies represent a change in the way in which we can construct, analyse and present observational research. To realise the full potential of this however, we must rethink some of the approaches associated with personal observation, audiotape and even analogue videotape. This paper examines the methodological issues of digital video data in observational studies and is informed by the authors' experiences in research involving doctors' and patients' interaction with the computers (see Table 1).

\section{DIGITAL VIDEO DATA \\ The advantages}

Video observation has two principal advantages over other observational techniques. It records more information than could otherwise be captured [i.e. density of information] and it allows retention of that information [i.e. permanence] (Grimshaw, 1982). Videorecordings should not, however, be seen as a total record of a social interaction, rather they constitute one part of a complete ethnographic approach (Corsaro, 1982), ideally informed by theory. Videotaping allows reviewing of the interaction at a number of sequential levels; the whole event, major constituents and then particular aspects of organisation within the event (Erickson, 1982). These elements of video make it particularly useful

TABLE 1: AN ANALYSIS OF HOW DOCTORS, PATIENTS AND COMPUTERS INTERACT IN THE CONSULTATION

Australian general practitioners (GPs) were advised of the study intentions and methods and then invited to participate in the study. Upon consent, a single camera was mounted in the consultation room. Patients were invited to participate on arrival at the clinic and consent was rechecked at the end of the consultation, in a two-stage process. The patient's consent or otherwise in no way influenced the treatment they received. The digital recordings were loaded into tagging software and tagged over several viewings (Pearce, Dwan, Phillips, \& Arnold, 2007). A frame of the tagging software is shown in Figure 1. Using a dramaturgical framework (Goffman, 1974) videos were then viewed sequentially and a conceptual framework developed (Pearce, Dwan, Arnold, Phillips, \& Trumble, 2009). Using the principles of hermeneutics, videos were then viewed and reviewed, applying aspects of the conceptual framework to specific parts of the consultation, such as the first minute (Pearce, Trumble, Arnold, Dwan, \& Phillips, 2008). 
for a hermeneutic interpretation of emotional nuances, embodied perceptions, spatial influences, relational understandings, situational factors and temporal manifestations (Raingruber, 2003), all things that have significance in the medical consultation. The hermeneutical advantages of digital video data will be discussed shortly.

Video has certain advantages compared to participant observation in a medical consultation; Medical consultations generally occur in a small space, where confidentiality is a key concern of all participants. Information revealed in the consultation is often of a highly personal nature, not intended for a wider audience. The insertion of another human in the room can be quite intrusive, whereas a video camera can be less so. Video observation has been used to a limited degree in research observing consultation behaviour. Two main models have been used: Using the video recording as a prompt for feedback from doctors and patients (Arborelius \& Timpka, 1990, 1991) and using the video as a source of data for an external observer (Frankel et al., 2005; Gibson, Jenkigns, Wilson, \& Purves, 2005; Greatbatch, Heath, Luff, \& Campion, 1995; Margalit, Roter, Dunevant, Larson, \& Reis, 2006; Rhodes et al., 2008; Ventres, Kooienga, Marlin, Vuckovic, \& Stewart, 2005).

Coleman (2000) summarised the advantages and disadvantages of using video observation in health research. Video recording is usually well tolerated by patients, with consent rates usually greater than $65 \%$ and often more than $80 \%$. Patients are more likely to decline if younger, female or psychologically distressed. There appears to be no change in doctor behaviour. Video observation has traditionally involved a single camera/ video stream, although more recently there have been attempts to combine both multiple streams with new software that allows pattern recognition (Kumarapeli, De Lusignan, Koczan, Jones, \& Sheeler, 2007). Whether there is an effect on patient behaviour by the intrusion of a video camera is difficult to study, but it is known that patients report having forgotten that the video camera was there (Coleman, 2000).

In any ethnographic study, two important components are entitled 'first' and 'second' order concepts (Miles \& Huberman, 2002). First order concepts are the 'facts' of an ethnographic investigation, easily observed or 'repeatable' things such as room layout, number of occurrences of specific events and so on. First order concepts also include the interpretations and theories of those observed. Second order concepts are the theories an analyst uses to organise those events and uses to interpret the theories and interpretations of those observed, a process Giddens calls 'a double hermeneutic' (Giddens, 1993). One of the principal effects of video is to increase the accessibility of the first order events - by the very nature of the repeatability and ease of viewing of the data, thereby increasing the amount of information to inform the development of second order concepts.

The use of digital video as a data source, coupled with appropriate software, is significantly different from and we would argue an improvement on, analogue data. Digital video and the flexibility of associated software greatly increase the capacity for analysis. They allow greater manipulation of the data thus facilitating a wider range of analyses. By way of example, in Figure 1 the video stream (left hand picture) can be shown at any speed: slowly for detailed identification of micro movements, or quite quickly for summary work. The ability to tag or mark particular elements (such as participant gaze in the example shown) allows those elements to be extracted as sample movies and run with similar elements from different observation times.

\section{The hermeneutical consequences}

All research should be framed around a solid understanding of some underlying principles, those of ontology, epistemology, theoretical perspective and methodology. To put it simply, all forms of data collection enshrine a distinctive version of reality (Coffey \& Atkinson, 1996). Yet all too often these principles are not adequately 


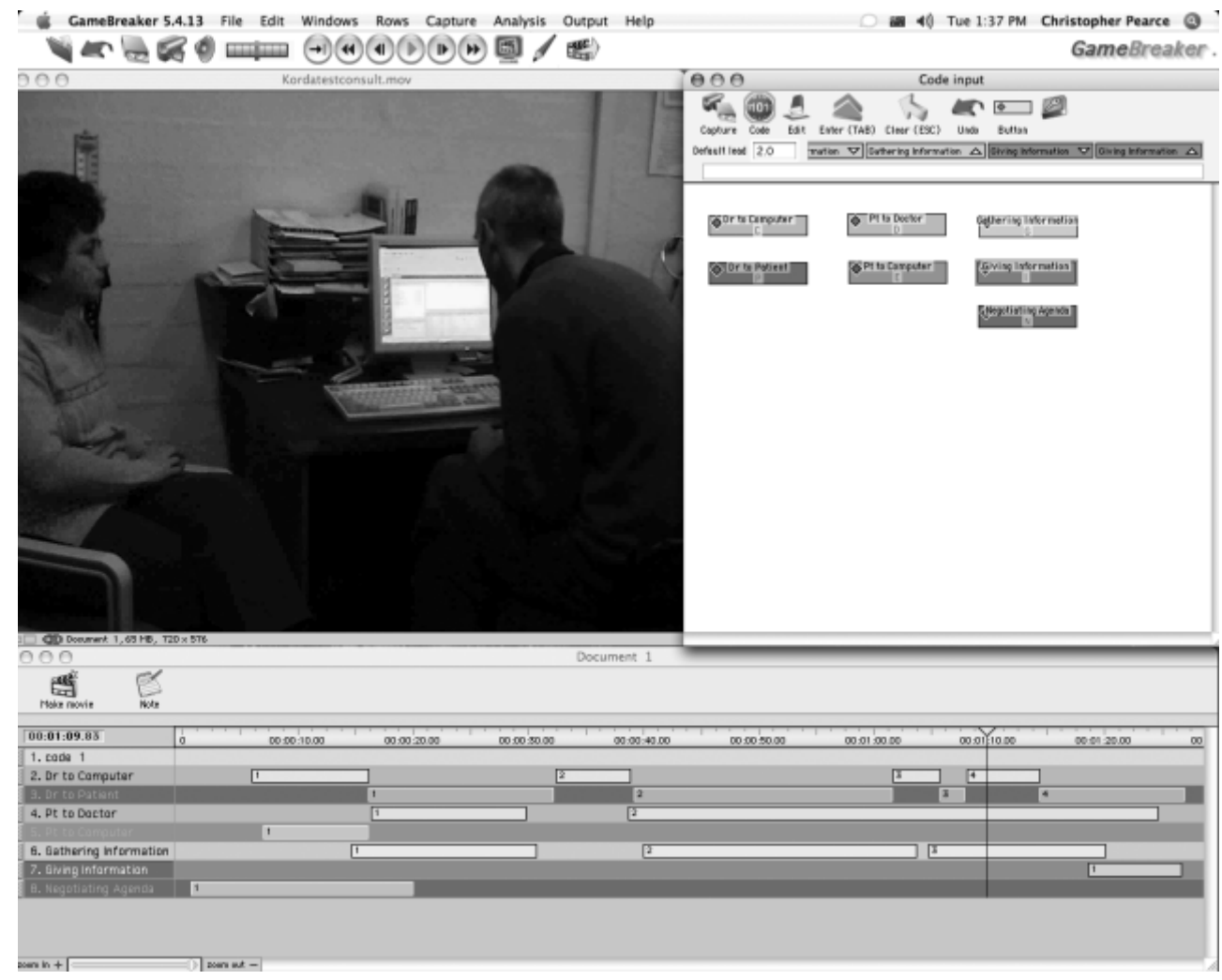

Figure 1: SCREEN SHOt From a VIEWING OF A tAGged CONSULtATION.

articulated either before or after the research, indeed, it is often the method that animates the research and subsumes the attention of the researchers. It is only later that the theoretical issues that underpin the methodology are discussed. In our case, we argue that digital video is a significantly different way of doing research, one that merits a rethink of some of these underlying methodological issues. Current qualitative techniques refer to theories of interpretation (hemeneutics) and human experience (phenomenology) (Malterud, 2001a). Video observation, particularly digital video, is particularly suited to hermeneutics. Initially hermeneutics was used to describe a method of interpreting religious texts, but its use has been widened to describe an interpretive process (Crotty, 1998: ch. 5). Whilst hermeneutics encompasses a variety of forms, notably 'critical hermeneutics', 'pure hermeneutics' and 'post-modern hermeneutics' (Myers, 2004), the approach may be broadly characterised through reference to four concerns. Firstly, hermeneutics is concerned with the means by which the meaning of a text, or importantly a text analogue such as video, may be arrived at. Secondly, this meaning circulates between the 'parts' and the 'whole', each informing the other through a process referred to as 'the hermeneutic circle'. Thirdly, preconceptions are regarded as important in establishing meaning and are not rejected a priori as sources of bias. Fourthly, a hermeneutic approach both treats the data as a distant thing and paradoxically assumes a relationship between the reader and the text, in a process called autonomisation and distanciation. Digital video allows this process by its very flexibility; it can be viewed as a whole, in small parts, reanalysed as new frameworks are 
developed. The preconceptions of the researcher are accommodated in the process, as is the relationship between the researcher and the data.

Much has been written about how researchers relate to their data. More so than any other method, observational techniques raise the issue of the relationship between the researcher and their subjects. Often ignored in this discussion is the relationship is the relationship between the readers (and other consumers of the results) have with the data. They are, after all, the desired endpoint of all research. In fact, given that research is about discovering new knowledge and communicating $i t$, then the problem is really about the relationship between the reader of the study and the data, with the researcher inserted in the middle as an interpretive element. The relationship between the researcher and their data occupies a great deal of thought - with a central concept being of the need for the researcher to understand their own position, their potential biases, their experiences and the influences that these might have on the research process, their ability to engage in a reflexive process, to become a reflexive practitioner (Alvesson \& Sköldberg, 2000; Malterud, 2001a). Just as important there is the relationship that then exists when that interpretive element is communicated to others.

\section{RELATIONSHIP BETWEEN READER AND RESEARCHER AND DATA}

The strength of observational research in anthropology and sociology has historically been the direct relationship between the researcher and the data source - the interacting humans involved in a social milieu. Yet the very richness and closeness led to problems in the presentation of the results. Whilst observations were recorded, much of the data was held in the researchers head, in their memories of the interaction. When the observations of the researchers were presented, they were hard for the reader to test, as the interaction was an evanescent phenomenon.

The presence of more permanent methods of recording, such as audiotapes, changed this tension between being 'in the present' of the subjects experience and later documentation. Now data (audio or video files) were permanent, and able to be archived and reviewed through secondary analysis by other researchers. This led to methods such as conversation analysis, whereby transcriptions of conversations are painstakingly detailed and then analysed. These transcriptions use visual cues to indicate stresses and intonation. Paradoxically, the researchers were now removed one step from the interaction, but the transcriptions were available to readers of the research. In effect, the closer the researchers come to the data, the further the readers are removed from it.

As an example, look at Figures 2 and 3. They represent specific sections of consultations from two separate studies. Superficially they look very similar, as representations from videos of consultations. But in fact they are quite different in purpose and representation. Figure 2 comes from a study that used conversation analysis as a method and is typical of many of the studies referred to earlier. What you see is the data that was used in the analysis, taken from the videotapes that were in turn taken of the interaction. The reader can see the data that the researcher used in reaching their conclusions.

Figure 3, on the other hand, comes from our research. As we have explained, our analysis was done on the moving pictures, not on any abstracted transcription. The figure is a representation of the data for the purposes of the reader - not the researcher - by way of illustration. The significant difference in this method to the previous studies is that this tagging process replaces the need for detailed transcriptions. Heath and Hindmarsh (2002) describe transcriptions as 'a path for the researcher through to the video data'; tagging on the other hand allows direct engagement. Rather than attempt to represent what happens in the video on paper, the tagging allows generation of specific pieces of video that can be viewed and analysed in isolation, as well as still being part of the whole. Thus the richness of the data is preserved and the hermeneutic circle, the whole to 


\section{(2a) [HY:2:1 Transcript One]}

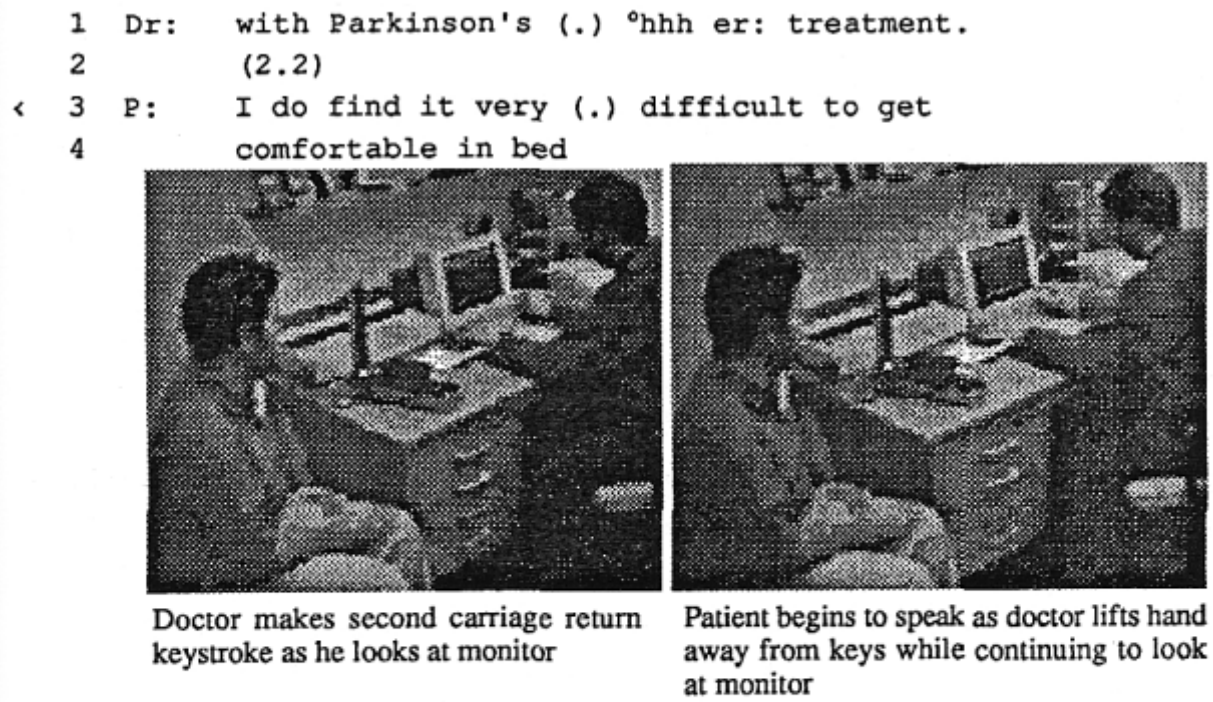

\section{(2b) [HY:2:1 Transcript Two: Detail of lines 1-3]}

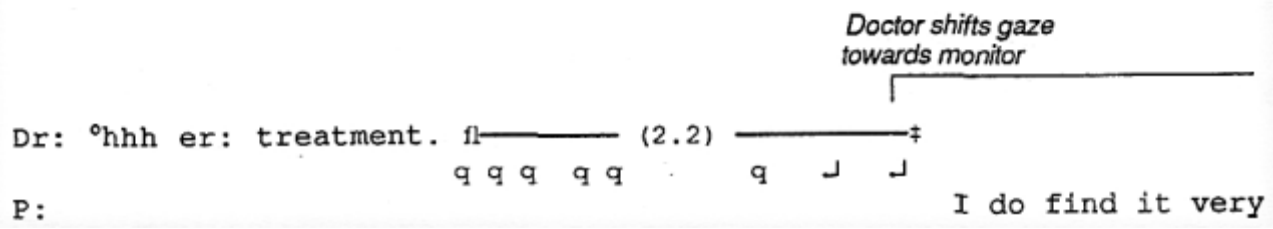

FIGURE 2: VIDEO TRANSCRIPT.

the part to the whole, is maintained. Such a process is not available to analogue techniques.

It is important to be clear that the software is not an analysis tool itself, but a sophisticated data management tool. Once tagged, the software can be searched by specific tags, or specific combinations of tags. From the tags the software generates short videos for viewing and analysis. It is designed for digital video, rather than other techniques that adapt paper based methods to the complexity of video.

\section{Ethical considerations}

The University of Melbourne Human Research Ethics Committee approved this research. However, the process by which ethics was approached in this study actually occurred at several levels and highlighted the complex ethical issues that pertain to this type of research. Hoeyer, Dahlager, and Lynoe (2005) describes how the ethical notions of social scientists can collide with medical scientists; so too did the differing concepts of ethics manifest themselves in this study. One of the researchers was personally familiar with videotaping real consultations, having used them extensively as part of the requirements of the training program for GPs in this country. Because this use was in a self-education, or audit environment, it did need the same ethical clearance that was required by the simple change of orientation to research. Wade (2005) has argued that this ethical divide is artificial and that the emphasis in all forms of patient interaction should be on the effects on 


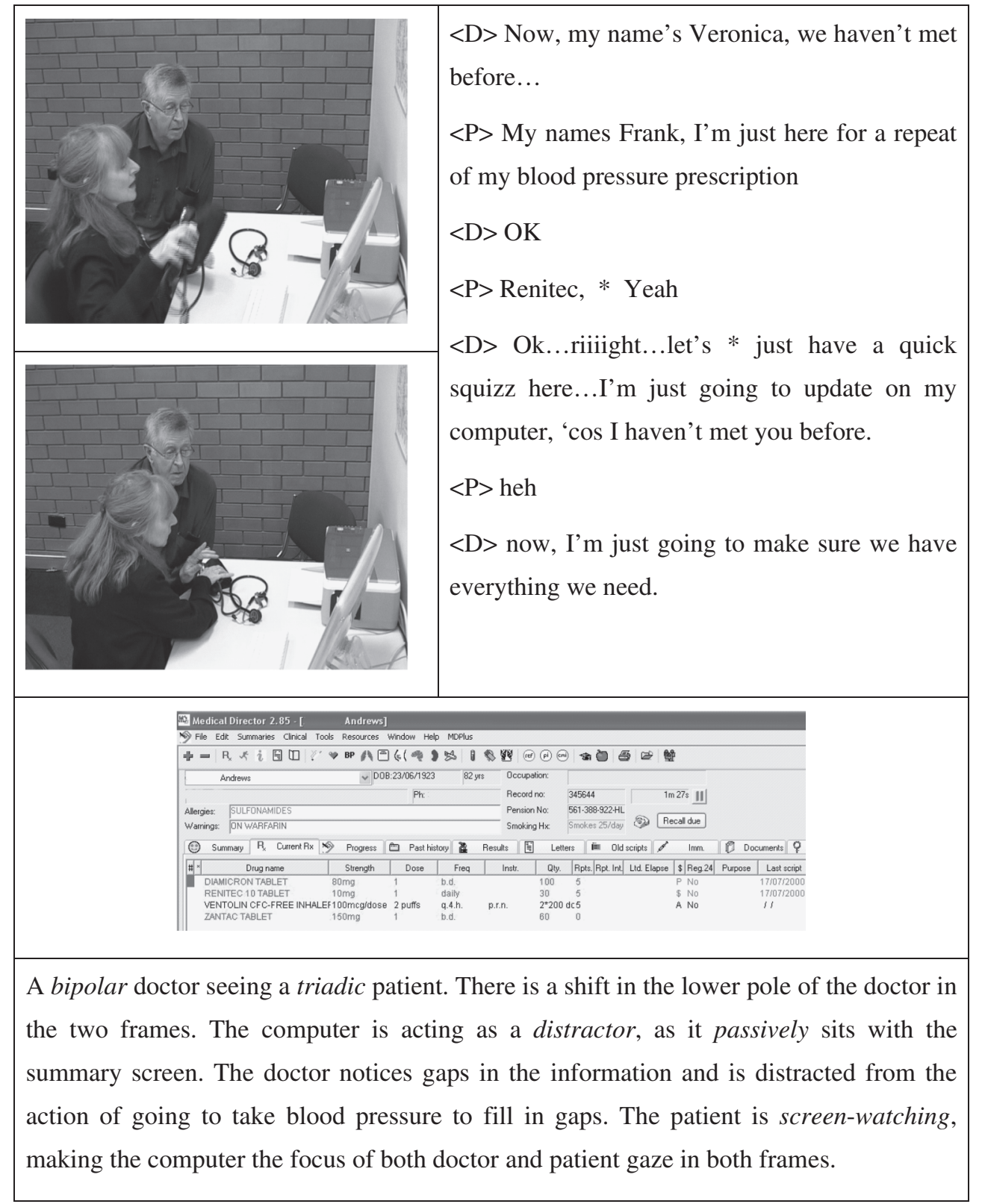

FIGURE 3: VIDEO REPRESENTATION.

the patient, regardless of the label applied to the activity (research, teaching, clinical). In the education environment, tapes are wiped after debriefing with the doctor-in-training, whereas in research they must be kept for several years after. The needs of the research community take precedence over the privacy risks to the subject. This is but one of the differences between an education versus a research environment. Others include the increased number of viewers of the tapes and the differing professional backgrounds of those viewing them. Patients in the 
educational environment are reassured that the viewers will all be doctors and therefore covered by the same ethical and confidentiality issues. In the UK, both the General Medical Council and the Royal College of General Practitioners have ethical guidelines with regard to the videotaping of patients. The former deals with videotaping in any circumstance and the latter has detailed guidelines specifically with respect to education and assessment roles (General Medical Council, 2005; Royal College of General Practitioners, 2005). Those guidelines formed the basis of the consent processes that we used.

Despite having passed the hurdle of institutional ethics, there was still a further step, namely convincing the doctors that the process of videotaping would not have a negative impact upon their patients. In contrast to the previous education environment where the GPs were familiar with regular videotaping, these GPs did not necessarily have any previous experience with videotaping or any form of observation of their work with patients. One of the commonest questions asked during the recruitment phase was with regard to the impact on their work and the confidentiality of the process and despite the best reassurances, it was a factor in many of the refusals by GPs (33\% of those contacted. They held the ethical issues to an even higher standard than the institutional ethics committee. With a patient refusal of only $7 \%$, it was the subjects who were most accepting of the process.

\section{Discussion}

The use of digital data has proven to be a wellaccepted and versatile medium for observational research in a health setting in many studies, however we believe it has yet to live up to its potential. We believe the advent of digital data, with its flexibility and ability to be manipulated by management software, will be the technological change that helps research using video data to blossom. It is not so much the addition of video that is significant here, as it is the digital nature of the source material. However, as with any technology, it must be seen only as a tool and not replacing the important theoretical and methodological issues. Being aware of the possibilities allows selection of appropriate methodologies and indeed adaptation of the existing methodologies. Many of the analytical techniques borrow from conversational analysis, where the nuances of speech are examined minutely. However, the visual context of that speech as seen on the video is just as significant, if not more so, than the length of the pause. But it does change the researchers' relationship with the data. It brings the researcher closer to the data, but moves the data further from the audience of articles such as this. Transcription techniques generate:

- interaction $\rightarrow$ video $\rightarrow$ transcription $\rightarrow$ analysis $\rightarrow$ reader

to be compared with methods such as ours (Figure 3), where it is:

- interaction $\rightarrow$ video $\rightarrow$ analysis $\rightarrow$ reader

Conversation analysis, with its complex notation system, represents a way of re-introducing some of that richness when compared to bare interview transcriptions. However, we would argue that having video data instead of audiotapes and particularly digital video data, magnifies the compromise made in that decision, as the extra data available from the video should not be ignored. There is potentially a wealth of difference between a doctor looking distractedly at a computer while asking 'how are you today' versus a doctor sitting forward engaging a patient whilst uttering the same words. Such nuances are not well captured by transcription techniques.

Conversely, the difference reflects compromises in the way results are presented. Figure 2 shows a sample of the actual data presented to readers to make their own decision. Figure 3 a representation of the data for researchers, an example of how analysis occurred as analysis is done on a moving image. This is in common, of course, with much observational data and methods must emphasise the way in which analysis is done. In contrast to participant or non-participant observation, video 
allows for observation of the same data by multiple observers, potentially improving the validity of the interpretations.

It is the use of the tagging software that changes this equation. It allows for easy implementation of a conceptual framework and allows for multiple viewings, easy re-analysis if a new aspect occurs and can generate short videos for microanalysis. Clips can be watched fast or slow, backwards and forwards and quite precise measurements can be made, or coarse generalisations. Using digital data is particularly suited to easy manipulation of the frames - selecting specific sequences is easy and fine grain stepping though short pieces of the consultation is a matter of dragging the mouse. If a new element appears as part of the analytical framework, videos can be reviewed and marked accordingly. Different videos can even be run simultaneously for comparison. Quantitative data (such as time staring at the computer) is a mouse click away. Additionally, poor quality videos can be adjusted - lighting improved or audio raised - which improves the source data and reduces errors.

\section{FinalLY}

Our original study is an example of a simple, well accepted method for the observation of a very private interaction. Its significance here is in a consideration of how digital video has the potential to add significantly to the methods available to researchers. It is another string to the bow, rather than a wholesale revolution. But its true potential will not be realised until it is considered in terms of what it offers in and of itself, rather than related to other methods. To re-interpret video in terms of conversational analysis, or indeed any other methodology, alone is to lose much of the richness of the data and its effects. Iedema, Forsyth, Georgiou, Braithewaite, and Westbrook (2007) talk of how video affected the researchers and the participants across the course of their research. Their study of pathology scientists was in effect a hybrid between observation and interview, with the subjects constantly interacting with the camera and observer. Others use multiple streams of video linked with screen capture to enhance the data sources (Kumarapeli et al., 2007). As a method of interaction analysis, digital video can be applied to a number of settings, methodologies and projects, but needs to be considered for the advantages it now offers.

\section{ACKNOWLEDGEMENTS}

Dr. Pearce was supported by an NH\&MRC scholarship, and the research was funded by an RACGP informatics fellowship. Neither organisation influenced the writing of this paper, and there are no other conflicts of interest.

\section{References}

Alvesson, M., \& Sköldberg, K. (2000). Reflexive methodology: New vistas for qualitative research. London: Sage.

Arborelius, E., \& Timpka, T. (1990). In what way may videotapes be used to get significant information about the patient-physician relationship? Medical Teacher, 12, 197-208.

Arborelius, E., \& Timpka, T. (1991). Comparison of patients' and doctors' comments on videorecorded consultations. Scandinavian Journal of Primary Health Care, 9, 71-77.

Coffey, A., \& Atkinson, P. (1996). Making sense of qualitative data: Complementary research strategies. Thousand Oaks, CA: Sage.

Coleman, T. (2000). Using video-recorded consultations for research in primary care: Advantages and limitations. Family Practice, 17, 422-427.

Corsaro, W. (1982). Something old and something new. Sociological Methods \& Research, 11, $145-165$.

Crotty, M. (1998). The foundations of social research: Meaning and perspective in the research process. St Leonards, NSW: Allen \& Unwin.

Erickson, F. (1982). Audiovisual records as a primary data source. Sociological Methods \& Research, 11, 213-233.

Frankel, R., Altschuler, A., George, S., Kinsman, J., Jimison, H., Robertson, N. R., et al. (2005). Effects of exam-room computing on clinicianpatient communication: A longitudinal qualitative study. Journal of General Internal Medicine, 20, 677-682. 
General Medical Council. (2005). Making and using visual and audio recordings of patients. Available from: http://www.gmc-uk.org/standards/default.htm.

Gibson, M., Jenkings, K., Wilson, R., \& Purves, I. (2005). Multi-tasking in practice: Coordinated activities in the computer supported doctorpatient consultation. International Journal of Medical Informatics. 74, 425-436.

Giddens, A. (1993). New rules of sociological method: A positive critique of interpretative sociologies. Cambridge, UK: Polity Press.

Goffman, E. (1974). Frame analysis: An essay on the organization of experience. York, PA: Northeastern University Press.

Greatbatch, D., Heath, C., Luff, P., \& Campion, P. (1995). Conversation analysis: Human-computer interaction and the general practice consultation. In A. Monk \& G. N. Gilbert (Eds.), Perspectives on HCI: Diverse approaches (pp. 152-190). London: Academic Press.

Grimshaw, A. (1982). Sound-image data records for research on social interaction. Sociological Methods \& Research, 11, 121-144.

Heath, C., \& Hindmarsh, J. (2002). Video, ethnography and situated conduct. In T. May (Ed.), Qualitative research in action (pp. 99-122). London: Sage.

Hoeyer, K., Dahlager, L., \& Lynoe, N. (2005). Conflicting notions of research ethics - The mutually challenging traditions of social scientists and medical researchers. Social Science \& Medicine, 61, 1741-1749.

Iedema, R., Forsyth, R., Georgiou, A., Braithewaite, J., \& Westbrook, J. (2007). Visibilising the effects of computerising clinical care. Qualitative Research Journal, 6, 15-30.

Kumarapeli, P., De Lusignan, S., Koczan, P., Jones, B., \& Sheeler, I. (2007). The feasibility of using UML to compare the impact of different brands of computer system on the clinical consultation. Informatics in Primary Care, 15, 245-253.

Malterud, K. (2001a). Qualitative research: standards, challenges and guidelines. Lancet, 358, 483-488.

Malterud, K. (2001b). The art and science of clinical knowledge: Evidence beyond measures and numbers. Lancet, 358, 397-400.
Margalit, S., Roter, D., Dunevant, M., Larson, S., \& Reis, S. (2006). Electronic medical record use and physician-patient communication: An observational study of Israeli primary care encounters. Patient Education and Counseling, 61, 134-141.

Mason, J. (2002). Qualitative researching. London: Sage.

Miles, M., \& Huberman, A. (2002). The qualitative researcher's companion. Thousand Oaks, CA: Sage.

Myers, M. (2004). Hermeneutics in information systems. In L. Willcocks \& J. Mingers (Eds.), Social theory and philosophy for information systems (pp. 205-222). Chichester: Wiley.

Pearce, C., Dwan, K., Arnold, M., Phillips, C., \& Trumble, S. (2009). Doctor, patient and computerA framework for the new consultation. International Journal of Medical Informatics 78, 32-38.

Pearce, C., Dwan, K., Phillips, C., \& Arnold, M. (2007). Analysing the doctor-patient-computer relationship: The use of video data. Informatics in Primary Care, 14, 221-226.

Pearce, C., Trumble, S., Arnold, M., Dwan, K., $\&$ Phillips, C. (2008). Computers in the new consultation: Within the first minute. Family Practice, 25, 202-208.

Popper, K. (1980). The logic of scientific discovery. London: Hutchinson.

Raingruber, B. (2003). Video-cued narrative reflection: A research approach for articulating tacit, relational and embodied understandings. Qualitative Health Research, 13, 1155-1169.

Rhodes, P., Small, N., Rowley, E., Langdon, M., Ariss, S., \& Wright, J. (2008). Electronic medical records in diabetes consultations: Participants' gaze as an interactional resource. Qualitative Health Research, 18, 1247-1263.

Royal College of General Practitioners. (2005). Video assessment of consulting skills in 2005. London: Workbook and Instructions.

Ventres, W., Kooienga, S., Marlin, R., Vuckovic, N., \& Stewart, V. (2005). Clinician style and examination room computers: A video ethnography. Family Medicine, 37, 276-281.

Wade, D. (2005). Ethics, audit and research: All shades of grey. British Medical Journal, 330, 468-471.

Received 14 September 2008 Accepted 12 October 2009 